\title{
ANTIOXIDANT POTENTIAL OF DIFFERENT PARTS OF BOGOR PINEAPPLE (ANANAS COMOSUS [L.] MERR. VAR. QUEEN) CULTIVATED IN WEST JAVA-INDONESIA
}

\author{
IRDA FIDRIANNY*, VELIANA VIRNA, MUHAMAD INSANU
}

Department of Pharmaceutical Biology, School of Pharmacy, Bandung Institute of Technology, Indonesia. Email: irdafidrianny@gmail.com Received: 15 August 2017, Revised and Accepted: 29 September 2017

\begin{abstract}
Objective: The aims of this research were to observe antioxidant activities from different parts of Bogor pineapple (Ananas comosus [L.] Merr. Var. Queen) using two antioxidant testing methods which were 2,2-diphenyl-1-picrylhydrazyl (DPPH) and ferric reducing antioxidant power (FRAP) and correlation of total phenolic and flavonoid contents with their inhibitory concentration $50 \%\left(\mathrm{IC}_{50}\right)$ of DPPH and exhibitory concentration $50 \%\left(\mathrm{EC}_{50}\right.$ ) of FRAP.
\end{abstract}

Methods: Each sample was extracted by reflux using different polarity solvents. Antioxidant activities were determined using DPPH and FRAP assays, total phenolic content (TPC) using Folin-Ciocalteu reagent, flavonoid content by Chang's method, and correlation with their IC $_{50}$ DPPH and EC $_{50}$ FRAP were analyzed by Pearson's method.

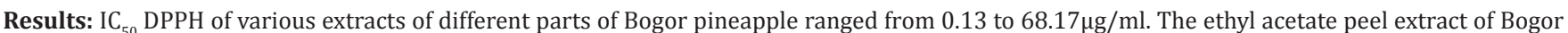
pineapple presented the highest TPC (7.84 g GAE/100 g) while the highest total flavonoid content (10.84 g QE/100 g) was shown by ethyl acetate bract extract of Bogor pineapple. TPC in peel extract of Bogor pineapple had negative and significant correlation with their EC ${ }_{50}$ FRAP. The IC $_{50}$ DPPH and $\mathrm{EC}_{50}$ FRAP of peel extract of Bogor pineapple showed positive and significant correlation.

Conclusion: All different part extracts of Bogor pineapple (except n-hexane flesh extract, peel extract, and bract extract) were categorized as a very strong antioxidant by DPPH method. Phenolic compounds in peel extract of Bogor pineapple were the major contributor in antioxidant activities by FRAP method. DPPH and FRAP methods gave linear results in antioxidant activities of Bogor pineapple peel extract.

Keywords: Antioxidant, 2,2-diphenyl-1-picrylhydrazyl, Ferric reducing antioxidant power, Bogor pineapple.

(C) 2018 The Authors. Published by Innovare Academic Sciences Pvt Ltd. This is an open access article under the CC BY license (http://creativecommons. org/licenses/by/4. 0/) DOI: http://dx.doi.org/10.22159/ajpcr.2018.v11i1.22022

\section{INTRODUCTION}

The excessive of free radical in oxidative stress condition can be scavenged by antioxidant, which related to many degenerative diseases. Phenolic compounds included flavonoid compounds have many effects such as antioxidant, antibacterial, and antidiabetic activities [1-4]. Phenolic compounds are commonly used as a subject in many researches. Many plants are resources of natural antioxidant because they contain phenolic and flavonoid compounds which have the antioxidant capacity [5-7].

Some methods have been used to determine antioxidant activity in many plants extracts such as 2,2-diphenyl-1-picrylhydrazyl (DPPH), ferric reducing antioxidant power (FRAP), and 2,2'-azinobis (3-ethylbenzthiazoline-6-sulfonic acid (ABTS) methods [8]. The previous researches [6,8] presented that DPPH, ABTS, and FRAP can be performed to observe antioxidant activity of fruits, vegetables, and food.

The previous researches revealed that pineapple contained flavonoid compounds and other phenolic compounds $[9,10]$ which can act as antioxidant. The previous study [11] presented that fruit pulp of pineapple (Ananas comosus) had antioxidant capacity. Parts of the plant may contain similar compounds, and hence, they have similar effects. Peel and bract of pineapple are waste of pineapple and may have antioxidant activity.

Bogor pineapple (A. comosus [L.] Merr. Var. Queen) is one variety of pineapple. There was no research regarding antioxidant activity of different parts of extract of Bogor pineapple (A. comosus [L.] Merr. Var. Queen] which were flesh, peel, and bract extracted using increasing polarity solvents (n-hexane, ethyl acetate, and ethanol) and observed by DPPH and FRAP assays.

The goals of this research were to observe antioxidant activities in various polarity extracts (n-hexane, ethyl acetate, and ethanol) from different parts of Bogor pineapple grown in West Java, Indonesia, using DPPH and FRAP assays and correlations of total phenolic and flavonoid with their antioxidant activities.

\section{MATERIALS AND METHODS}

Materials

DPPH, 2,4,6-tripyridyl-S-triazine (TPTZ), gallic acid, and quercetin were purchased from Sigma-Aldrich (MO, USA), different parts of Bogor pineapple (A. comosus). All of other reagents were analytical grades.

\section{Preparation of sample}

Bogor pineapple was collected from Bogor, West Java, Indonesia, and determined as Bogor pineapple (A. comosus [L.] Merr. Var. Queen) at Herbarium Bandungense, School of Life Sciences and Technology, Bandung Institute of Technology. Different parts of Bogor pineapple which were used in this research: Flesh named as flesh of Bogor pineapple (FLE), peel as peel of Bogor pineapple (PEE), and bract as bract of Bogor pineapple (BRC), thoroughly washed with tap water, sorted while wet, cut, dried, and grinded into powder. Peel and bract are the waste product which not used by the people.

\section{Extraction}

Each sample was extracted by reflux using different polarity solvents. Three hundred grams of powdered samples was extracted using $\mathrm{n}$-hexane was repeated 3 times. The remaining residue was then 
extracted triplicate using ethyl acetate. Finally, the remaining residue was extracted triplicate using ethanol. Therefore, totally, there were nine extracts: Three n-hexane extracts (namely, FLE1, PEE1, and BRC1), three ethyl acetate extracts (FLE2, PEE2, and BRC2), and three ethanolic extracts (FLE3, PEE3, and BRC3).

\section{Antioxidant activity by DPPH assay}

Antioxidant activity by DPPH assay was performed using Blois's method [12] with minor modification. Two ml of various concentration of each extract was added into $2 \mathrm{ml} \mathrm{DPPH} 50 \mu \mathrm{g} / \mathrm{ml}$ to initiate the reaction for obtaining a calibration curve. The absorbance was observed after 30 min incubation at wavelength $515 \mathrm{~nm}$ by UV-Vis spectrophotometer (Beckman Coulter DU 720). Ascorbic acid was used as a standard, methanol as a blank, and DPPH $50 \mu \mathrm{g} / \mathrm{ml}$ as a control. The analysis was done in triplicate for standard and each extract. Antioxidant activity was presented as inhibitory concentration 50\% $\left(\mathrm{IC}_{50}\right)$ of DPPH scavenging activity by calculating $\mathrm{IC}_{50}$ of each extract using its calibration curve.

\section{Antioxidant activity by FRAP assay}

Antioxidant capacity by FRAP method was conducted by Benzi's method with minor modification [13]. FRAP solution was prepared in acetate buffer pH 3.6. $2 \mathrm{ml}$ of various concentration of each extract was added into $2 \mathrm{ml}$ FRAP solution $50 \mu \mathrm{g} / \mathrm{ml}$ to initiate the reaction. After 30 min incubation, the absorbance was observed at wavelength $593 \mathrm{~nm}$. Acetate buffer was used as a blank, FRAP $50 \mu \mathrm{g} / \mathrm{ml}$ as control, and ascorbic acid as standard. The analysis was performed in triplicate for standard and each extract. Antioxidant capacity was expressed as exhibitory concentration $50 \%\left(\mathrm{EC}_{50}\right)$ of FRAP capacity by determining $\mathrm{EC}_{50}$ using its calibration curve.

\section{Total phenolic content (TPC)}

TPC was determined using Folin-Ciocalteu reagent [14]. The absorbance was seen at wavelength $765 \mathrm{~nm}$. The analysis was conducted in triplicate for each extract. Gallic acid solution $50-160 \mu \mathrm{g} / \mathrm{ml}$ was used to observe a calibration curve. TPC was presented as gallic acid equivalent per $100 \mathrm{~g}$ extract (g GAE/100 g).

\section{Total flavonoid content (TFC)}

Determination of TFC was performed using a modification of Chang's method [15]. The absorbance was determined at wavelength $415 \mathrm{~nm}$. The analysis was carried out in triplicate for each extract. Quercetin standard 50-125 $\mu \mathrm{g} / \mathrm{ml}$ was used to obtain a calibration curve. TFC was exposed as g quercetin equivalent per $100 \mathrm{~g}$ extract (g QE/100 g).

\section{Statistical analysis}

Each sample analysis was performed in triplicate. All of presented results are means ( \pm standard deviation) of three independent experiments. Statistical analysis using ANOVA with a statistical significance level set at $\mathrm{p}<0.05$ and post hoc Tukey procedure was carried out with the SPSS 16 for Windows. Correlation between the total phenolic and flavonoid content and antioxidant activities and correlation between two antioxidant testing methods were analyzed using the Pearson's method.

\section{RESULTS AND DISCUSSION}

Extraction of each crude drug sample was conducted using three different polarity solvents, to separate component in crude drug based on their polarity. Non-polar compound was extracted triplicate using n-hexane solvent. The residue of crude drug was extracted triplicate by ethyl acetate solvent to separate most of semi-polar compound. Then, the crude drug residue was separated by ethanol solvent to obtain most of the polar compound.

The activities and phytochemical content among the extracts can be compared if density among the extracts were similar. One extract with high density may show the higher activity and higher phytochemical content than low-density extract. Hence, all extracts (nine extracts) which were used in the present study should be prepared in similar density. The density of extract did not evaluate in $100 \%$ concentrated extract, due to its difficult to determine density of concentrated extract using pycnometer, so the density of the extracts was revealed as density $1 \%$ extract (Table 1 ).

Apak et al. [16] stated that there are two category antioxidant assays, which are single electron transfer (SET)-based assay and hydrogen atom transfer (HAT)-based assay. SET is based on the ability of antioxidant to transfer one electron to reduce oxidant, meanwhile HAT based on the ability of antioxidant to quench radical by hydrogen donation [17]. Increasing or decreasing in absorbance at a given wavelength is depended to the concentration of antioxidant in sample, will be shown by changing of color degree [16]. SET and HAT mechanisms almost always occur together. Ionization potential $(\Delta \mathrm{IP})$, bond dissociation energy (BDE), redox potential, $\mathrm{pH}$, and solvent will influence the predominant mechanism will be occurred $[16,17]$. HAT mechanism compound will be predominantly if compound has $\Delta \mathrm{IP}$ $<-36 \mathrm{kcal} / \mathrm{mol}$, meanwhile SET with DIP >-45 kcal/mol [17].

\section{Antioxidant activity by DPPH assay}

DPPH is free radical and has absorption at wavelength $516 \mathrm{~nm}$. Antioxidant will transfer the hydrogen atom to scavenge DPPH free radical, and then, DPPH will stable. DPPH in methanol gives the purple color and the color change to yellow when free radicals are scavenged by antioxidant [18]. Decreasing in absorbance of DPPH is correlated to antioxidant potential. IC $\mathrm{I}_{50}$ of DPPH scavenging activity is a concentration of sample or standard that can inhibit $50 \%$ of DPPH radical activity. The lowest $\mathrm{IC}_{50}$ is the highest antioxidant activity. $\mathrm{IC}_{50}$ was used to evaluate antioxidant activity of the sample and compared to standard.

Sample was categorized a very strong antioxidant if had $\mathrm{IC}_{50}$ lower than $50 \mu \mathrm{g} / \mathrm{ml}$, strong antioxidant 50-100 $\mu \mathrm{g} / \mathrm{ml}$, medium antioxidant 101 $150 \mu \mathrm{g} / \mathrm{ml}$, while $\mathrm{IC}_{50}>150 \mu \mathrm{g} / \mathrm{ml}$ a weak antioxidant [12]. IC ${ }_{50} \mathrm{DPPH}$ in various extracts of Bogor pineapple parts was exposed in Fig. 1 and compared to $\mathrm{IC}_{50} \mathrm{DPPH}$ of the ascorbic acid standard.

Li et al. [19] studied regarding major polyphenolic extract in Bali pineapple peel stated that methanol peel extract of Bali pineapple which was extracted by reflux method had $\mathrm{IC}_{50}$ DPPH $1.13 \mathrm{mg} / \mathrm{ml}$ categorized as a weak antioxidant $\left(\mathrm{IC}_{50}>150 \mu \mathrm{g} / \mathrm{ml}\right)$. It was different with the present study which demonstrated that ethanolic peel extract of Bogor pineapple showed IC $_{50}$ DPPH $0.13 \mu \mathrm{g} / \mathrm{ml}$ classified as a very strong antioxidant. The previous research presented that methanol fruit pulp extract of MD2 genotype pineapple gave the highest DPPH scavenging activities (22.85 $\mu \mathrm{mol} \mathrm{TE} /$ fresh weight) among $26 \mathrm{six}$ genotypes of pineapples from China [11]. A study by Kongsuwan et al. [20] exhibited that frozen fruit pulp Nanglae pineapple showed higher DPPH scavenging activity (152.93 mol TE/100 g fresh weight) than Phulae pineapple (118 mol TE/100 g fresh weight). Haripyaree et al. [21] extracted phenolic compound of pineapple fruit using ethyl acetate solvent in twice, and then, the extract was dissolved in methanol. Percentage of DPPH radical scavenging activities of the extract $15 \mu \mathrm{g} / \mathrm{ml}$ was $52.2 \%$ higher than ascorbic acid $30.7 \%$ and pyrogallol 38.2\%. Previous research [22] presented that methanol peel extract of pineapple waste from Egypt with concentration of $8 \mathrm{mg} / \mathrm{ml}$ had the highest percentage of DPPH scavenging activities compared to $2,4,6$, and $10 \mathrm{mg} / \mathrm{ml}$, and the fermented pineapple waste (FPW) showed higher percentage of DPPH scavenging activities than un FPW (UFPW).

Table 1: Density of various extracts of Bogor pineapple

\begin{tabular}{llll}
\hline Sample & \multicolumn{2}{c}{ Density 1\% extract $(\mathrm{g} / \mathrm{ml})$} & \\
\cline { 2 - 4 } & N-hexane extract & $\begin{array}{l}\text { Ethyl acetate } \\
\text { extract }\end{array}$ & Ethanol extract \\
\hline Flesh & 0.66 & 0.85 & 0.75 \\
Peel & 0.67 & 0.84 & 0.75 \\
Bract & 0.69 & 0.84 & 0.76 \\
\hline
\end{tabular}


Antioxidant activities can be demonstrated by percentage of DPPH scavenging activity and compared to percentage of DPPH scavenging activity of ascorbic acid as standard. The percentage of DPPH scavenging activity of ascorbic acid did not achieve $100 \%$ because there was still residual yellow color in solution after antioxidant giving hydrogen atom to DPPH $[23,24]$. The percentage of DPPH scavenging activity cannot present the real antioxidant activity because the higher concentration of sample does not always give the higher percentage of DPPH scavenging activity. The linear result will be exposed in some concentration only. It can be seen in the previous study, which showed that methanol peel extract of pineapple from Nigeria which was extracted by maceration with concentrations of $25 \mu \mathrm{g} / \mathrm{ml}$, $50 \mu \mathrm{g} / \mathrm{ml}, 100 \mu \mathrm{g} / \mathrm{ml}, 200 \mu \mathrm{g} / \mathrm{ml}$, and $400 \mu \mathrm{g} / \mathrm{ml}$ had percentage of DPPH scavenging activities 95.52\%, 95.67\%, 95.74\%, 95.17\%, and $94.96 \%$, respectively [25]. The methanolic peel extract $100 \mu \mathrm{g} /$ $\mathrm{ml}$ gave a higher percentage of DPPH scavenging activity (95.74\%) than methanolic peel extract $200 \mu \mathrm{g} / \mathrm{ml}(95.17 \%)$ and $400 \mu \mathrm{g} / \mathrm{ml}$ (94.96\%). This condition can be occurred in extract or sample which contained more than one compound. The extract consisted of many compounds. Maybe some of them have antioxidant activities, and the other compounds may act as an antagonist of antioxidant activities. The compounds will act as antagonist of antioxidant activities if their minimum effective concentration has been reached. In methanolic peel extract, $200 \mu \mathrm{g} / \mathrm{ml}$ above may be the antagonist antioxidant compounds reached their effective minimum concentration and against the effect of antioxidant activity, and hence, the percentage of DPPH will be decreased. Therefore, this reason can explain why the extract with lower concentration can give higher activity than higher concentration.

\section{Antioxidant activity by FRAP assay}

The reducing capacity was a significant indicator for antioxidant potential [22]. The presence of Fe (III) can be catalyzed a reaction in the human body which was related to the presence of free radical. In FRAP method, antioxidant will reduce Fe (III) to Fe (II), and then, Fe (II) will form a complex with TPTZ in acetate buffer $\mathrm{pH}$ 3.6. Complex of Fe (II)-TPTZ shows blue color and gave absorption at maximum wavelength $593 \mathrm{~nm}$. The reduction potential of $\mathrm{Fe}$ (III)/Fe (II) $0.77 \mathrm{~V}$, hence, an antioxidant compound will reduce Fe (III) to Fe (II) if its reduction potential lower than $0.77 \mathrm{~V}$. Increasing in absorbance of Fe (II)-TPTZ related with antioxidant capacity. $\mathrm{EC}_{50}$ of FRAP capacity is a concentration of sample or standard that can exhibit $50 \%$ of FRAP capacity. $\mathrm{EC}_{50}$ FRAP of each extract was compared to $\mathrm{EC}_{50} \mathrm{DPPH}$ of ascorbic acid standard and can be seen in Fig. 2 .

Previous research found that frozen fruit pulp of Nanglae pineapple gave higher FRAP capacity (205.73 mol AAE/100 g fresh weight) than Phulae pineapple $165.28 \mathrm{~mol} \mathrm{AAE} / 100 \mathrm{~g}$ fresh weight [20]. Lu et al. [11] exposed that methanolic fruit pulp extract of MD2 pineapple genotype had the highest antioxidant activity by TEAC method $(17.30 \mu \mathrm{mol}$ TE/g fresh weight) among 26 six genotypes of pineapple. The present study demonstrated that $\mathrm{EC}_{50}$ FRAP of various extracts of different parts of Bogor pineapple varied from 97.34 to $370.16 \mu \mathrm{g} / \mathrm{ml}$, while the ethanolic extract of flesh, peel, and bract extract of Bogor pineapple showed $\mathrm{EC}_{50}$ FRAP $375.58,259.08$, and $370.16 \mu \mathrm{g} / \mathrm{ml}$, respectively. A study by Rashad et al. [22] revealed that methanolic peel extract of FPW $8 \mathrm{mg} / \mathrm{ml}$ showed the highest antioxidant activity by reducing power and beta-carotenelinoleic acid assays compared to concentrations of 2, 4, 6, and $10 \mathrm{mg} /$ $\mathrm{ml}$ and methanolic peel extract of UFPW. This result also expressed that higher concentration extract did not always gave higher activity than lower concentration. It is different from a pure compound which shows the higher concentration always gave higher activity.

TPC

TPC among the various extracts from different parts of Bogor pineapple was stated in terms of gallic acid equivalent and gave different result ranged from 0.47 to $7.84 \mathrm{~g} \mathrm{GAE} / 100 \mathrm{~g}$. PEE2 extract (ethyl acetate peels extract of Bogor pineapple) showed the highest TPC (7.84 g GAE/100 g) and the lowest for ethanolic flesh extract of Bogor pineapple (FLE3)0.47 g GAE/100 g (Fig. 3).

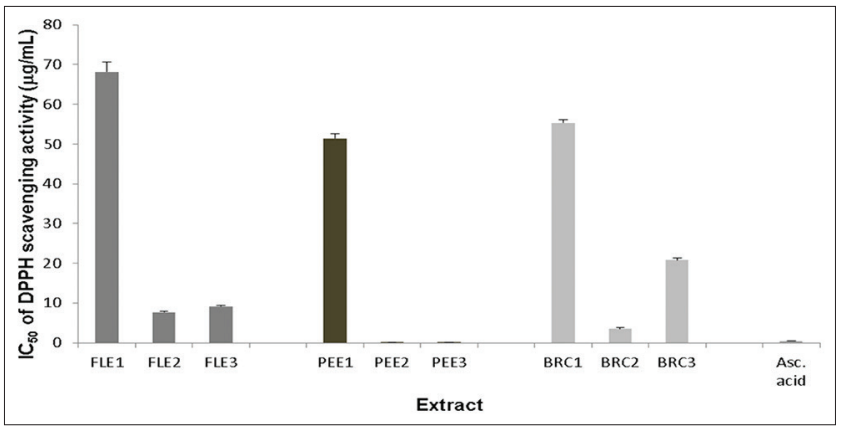

Fig. 1: Inhibitory concentration $50 \%$ of 2,2-diphenyl-1picrylhydrazyl scavenging activity in various extracts of Bogor pineapple $(n=3)$

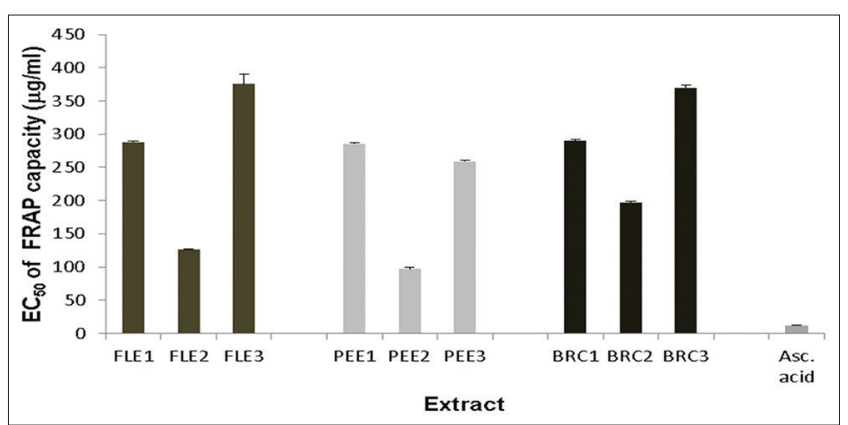

Fig. 2: Exhibitory concentration $50 \%$ of ferric reducing antioxidant power capacity in various extracts of Bogor pineapple $(n=3)$

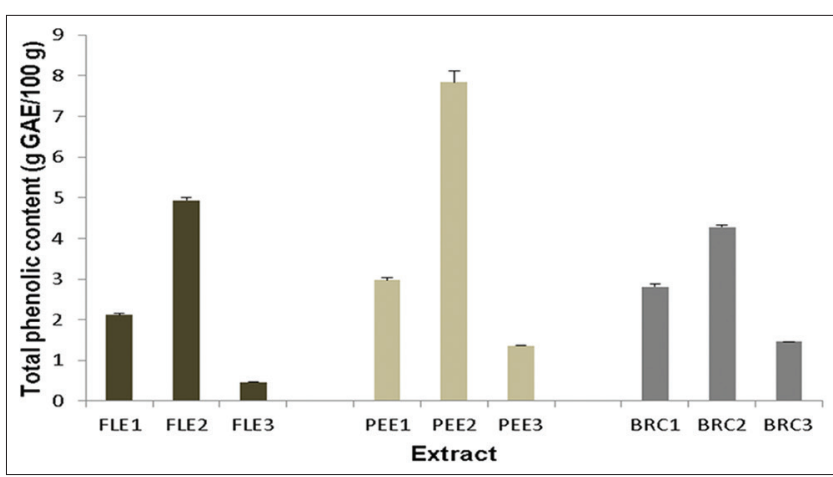

Fig. 3: Total phenolic content in various extracts of Bogor pineapple $(n=3)$

Flavonoids, tannins, and phenolic acids are included in phenolic groups. The stronger antioxidant capacity will be given by ortho and para hydroxyl substitution [26]. Cinnamic acid had higher antioxidant capacity than benzoic acid [27]. Antioxidant activity might be related to TPC $[14,28]$

Previous research [19] showed that methanolic peel extract of Bali pineapple had TPC $0.798 \mathrm{~g}$ GAE/100 g dry weight or $0.148 \mathrm{~g} / 100 \mathrm{~g}$ fresh weight. It was different from the present study which stated that TPC in ethanolic peel extract of Bogor pineapple $1.36 \mathrm{~g} \mathrm{GAE} / 100 \mathrm{~g}$ dry weight. A study by Kongsuwan et al. [20] presented that TPC and vitamin $\mathrm{C}$ of frozen fruit pulp of Phulae pineapple (26.20 mg GAE/100 g and $18.88 \mathrm{mg} / 100 \mathrm{~g}$ fresh weight, respectively) were higher than Nanglae pineapple (20.28 mg GAE/100 $\mathrm{g}$ and $6.45 \mathrm{mg} / 100 \mathrm{~g}$ fresh weight). The previous study [11] expressed that TPC in methanolic fruit pulp extract of MD2 pineapple genotype (77.55 mg GAE/100 $\mathrm{g}$ fresh weight) was the highest TPC among 26 six pineapple genotypes. The methanolic peel extract of pineapple from Egypt exhibited that FPW showed higher TPC than UFPW [22]. 
Table 2: Pearson's correlation coefficient of total phenolic and flavonoid content in various extracts of Bogor pineapple with their antioxidant activities

\begin{tabular}{llllll}
\hline Antioxidant parameter & \multicolumn{4}{l}{ Pearson's correlation coefficient (r) } \\
\cline { 2 - 5 } & TPC & TFC & EC $_{50}$ FRAP FLE & EC $_{50}$ FRAP PEE & EC $_{50}$ FRAP BRC \\
\hline IC $_{50}$ DPPH FLE & $-0.17 \mathrm{~ns}$ & $0.14 \mathrm{~ns}$ & $0.19 \mathrm{~ns}$ & $0.61^{*}$ \\
$\mathrm{IC}_{50}$ DPPH PEE & $-0.28 \mathrm{~ns}$ & $0.45 \mathrm{~ns}$ & & \\
$\mathrm{IC}_{50}$ DPPH BRC & $-0.35 \mathrm{~ns}$ & $0.13 \mathrm{~ns}$ & & $0.37 \mathrm{~ns}$ \\
$\mathrm{EC}_{50}$ FRAP FLE & $-0.99^{* *}$ & $-0.94^{* *}$ & & \\
$\mathrm{EC}_{50}$ FRAP PEE & $-0.93^{* *}$ & $-0.43 \mathrm{~ns}$ & & \\
$\mathrm{EC}_{50}$ FRAP BRC & $-0.99^{* *}$ & $-0.87^{* *}$ & & \\
\hline
\end{tabular}

IC $_{50}$ DPPH: Inhibitory concentration $50 \%$ of 2,2-diphenyl-1-picrylhydrazyl scavenging activity, $\mathrm{EC}_{50}$ FRAP: Exhibitory concentration $50 \%$ of ferric reducing antioxidant power capacity, FLE: Flesh of Bogor pineapple, PEE: Peel of Bogor pineapple, BRC: Bract of Bogor pineapple, TPC: Total phenolic content, TFC: Total flavonoid content, ns: Not significant, *significant at $\mathrm{p}<0.05,{ }^{* *}$ significant at $\mathrm{p}<0.01$

It can be seen in Fig. 3, TPC in ethyl acetate flesh extract of Bogor pineapples (FLE2), $4.93 \mathrm{~g}$ GAE/100 g dry weight was similar to TPC in ethyl acetate extract of bract (pineapple waste) (BRC2) $4.28 \mathrm{~g}$ GAE/100 g dry weight, but antioxidant activity of FLE2 was lower than BRC2, by DPPH method. It was presented by IC ${ }_{50}$ DPPH of FLE2 $(7.64 \mu \mathrm{g} /$ $\mathrm{ml}$ ) was higher than $\mathrm{IC}_{50}$ DPPH of BRC2 $(3.52 \mu \mathrm{g} / \mathrm{ml})$. Based on the result, it can be predicted that many phenolic compounds in FLE2 had low antioxidant activities. Meanwhile, BRC2 contained many phenolic compounds with high antioxidant activities.

TPC in ethanolic peel extract of Bogor pineapple (PEE3)1.36 g GAE/100 g dry weight was similar to TPC in ethanolic bract extract (BRC3) $1.46 \mathrm{~g}$ GAE/100 g dry weight; however, antioxidant activities of BRC3 was lower than PEE3, by FRAP method. EC ${ }_{50}$ FRAP of BRC3 $(370.16 \mu \mathrm{g} / \mathrm{ml})$ was higher than $\mathrm{EC}_{50}$ FRAP of PEE3 $(259.08 \mu \mathrm{g} / \mathrm{ml})$. It can be supposed that many phenolic compounds in PEE3 had high antioxidant activities, while only a little phenolic compounds in BRC3 with high antioxidant activities.

\section{TFC}

TFC among three part extracts of Bogor pineapple was figured in terms of quercetin equivalent in the range of $0.17-10.84 \mathrm{~g} \mathrm{QE} / 100 \mathrm{~g}$. The lowest TFC was given by ethanolic peel extract of Bogor pineapple (PEE3)0.17 g QE/100 g, while the highest TFC (10.84 g QE/100 g) presented by ethyl acetate bract extract of Bogor pineapple (BRC2) (Fig. 4).

A research by Lu et al. [11] regarding TFC in methanolic fruit pulp extract of 26 six pineapple genotypes forms China which grown with the same geographical conditions. The results found that TFC in Comte de Paris pineapple genotype gave the highest TFC $(0.0345 \mathrm{~g} \mathrm{RE} / 100 \mathrm{~g}$ fresh weight). It was different from the present study which exposed that TFC in ethanolic flesh extract of Bogor pineapple was $0.73 \mathrm{~g}$ $\mathrm{QE} / 100 \mathrm{~g}$ dry weight.

Flavonoid may have antioxidant effect as a hydrogen-donating compound, metal chelating ion, single oxygen transfer, and singlet oxygen quencher [29]. Hydrogen donating and metal chelating are related to ortho di-OH structure in ring $\mathrm{B}, \mathrm{C}-2-\mathrm{C}-3$ double bond, and oxo group at C-4 [29]. Flavonoid had higher antioxidant capacity than phenolic acid [27]. Flavonoid would give higher antioxidant capacity if flavonoid had ortho di-OH in C 3', ', - $-\mathrm{OH}$ in $\mathrm{C} 3$, oxo function in $\mathrm{C} 4$, and double bond at $\mathrm{C} 2$ and C3. The di-OH with ortho position in C3'-C4' had the highest influence to antioxidant capacity of flavonoid. The flavonoid glycosides had lower antioxidant capacity than flavonoid aglycones [27]. Data in Fig. 4 revealed that TFC in ethanolic peel extract of Bogor pineapple (PEE3)0.17 g QE/100 g dry weight was lower than TFC in ethanolic bract extract (BRC3) $0.37 \mathrm{~g} \mathrm{QE} / 100 \mathrm{~g}$ dry weight, but the antioxidant activity of PEE3 higher than BRC3, by DPPH method. It was presented by IC $_{50}$ DPPH of PEE3 $(0.13 \mu \mathrm{g} / \mathrm{ml})$ which was lower than IC $\mathrm{C}_{50}$ DPPH of BRC3 $(20.78 \mu \mathrm{g} / \mathrm{ml})$. Based on the result, it can be predicted that many flavonoid compounds in PEE3 had ortho di-OH in $\mathrm{C} 3^{\prime}, 4^{\prime},-\mathrm{OH}$ in $\mathrm{C} 3$, oxo function in $\mathrm{C} 4$, and double bond at $\mathrm{C} 2$ and $\mathrm{C} 3$

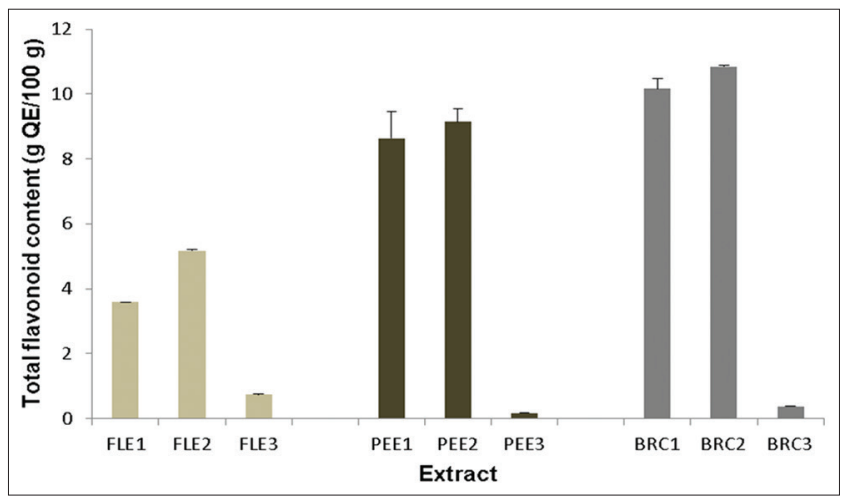

Fig. 4: Total flavonoid content in various extracts of Bogor pineapple $(n=3)$

which had high antioxidant activities, meanwhile only a little flavonoid compounds in BRC3 with high antioxidant activities.

\section{Pearson correlation coefficient}

Pearson's correlation coefficient was significantly negative if $-0.61 \leq$ $r \leq-0.97$ and significantly positive if $0.61 \leq r \leq 0.97$ [8]. The highest antioxidant activity will be shown by the lowest IC $_{50}$ of DPPH scavenging activities and $\mathrm{EC}_{50}$ of FRAP capacity. Increasing in TFC and TPC may be related with increasing in antioxidant activities, which was exposed by lower $\mathrm{IC}_{50}$ DPPH and $\mathrm{EC}_{50}$ of FRAP. Hence, the good correlation between TPC and TFC with $\mathrm{IC}_{50}$ DPPH or $\mathrm{EC}_{50}$ FRAP was significantly negative correlation [30]

TPC in peel extract of Bogor pineapple had a significant and negative correlation with their EC50 FRAP capacities $(r=-0.93, p<0.01)$ (Table 2). It can be seen that phenolic compounds were the major contributor in antioxidant capacities of Bogor pineapple peel extracts (PEE) by FRAP method. IC ${ }_{50}$ DPPH of Bogor pineapple peel extracts (PEE) had a significant and positive correlation with their $\mathrm{EC}_{50}$ FRAP. It can be concluded that DPPH and FRAP methods gave linear result in antioxidant activities of Bogor pineapple peel extracts.

The previous study [11] exposed antioxidant activities of methanol fruit pulp extract in terms of mol Trolox equivalent (TE)/g fresh weight. Therefore, the higher antioxidant activities will demonstrate by higher mol TE/g fresh weight. Methanol fruit pulp extract of MD2 pineapple genotype gave the highest TPC and also presented the highest antioxidant activities by DPPH and TEAC methods. It was proved by statistical analysis that TPC in methanol fruit pulp extract of MD2 pineapple genotype had significant and positive correlation with their antioxidant activities by DPPH and TEAC methods $(r=0.802 ; r=0.806$, $\mathrm{p}<0.01$, respectively), and hence, phenolic compounds were the major contributor in antioxidant activities of MD2 pineapple genotype by DPPH and TEAC methods. DPPH and TEAC methods gave positive and significant correlation in antioxidant activities of methanol fruit pulp 
extract of MD2 pineapple genotype $(r=0.912, \mathrm{p}<0.01)$. TPC in frozen fruit pulp of Phulae and Nanglae pineapple from Thailand had a higher correlation with their antioxidant capacities by FRAP method $(\mathrm{r}=0.78$, $\mathrm{p}<0.01$ ) [20]. It was similar to the present study which demonstrated that TPC and TFC in flesh extract and bract extract of Bogor pineapple had a significant correlation with their $\mathrm{EC}_{50}$ FRAP. It can be concluded that phenolic compounds in flesh and bract extracts of Bogor pineapple together with flavonoid compounds contributed in their antioxidant activities by FRAP method.

\section{CONCLUSION}

Antioxidant activities should be performed by different methods in parallel, due to various methods could give different results. All different parts of the extracts of Bogor pineapple (A. comosus [L.] Merr. Var. Queen) except n-hexane flesh extract, peel extract, and bract extract can be classified as a very strong antioxidant, using DPPH assay. Phenolic compounds in peel extracts of Bogor pineapple were the major contributor in their antioxidant activity by FRAP method. DPPH and FRAP methods gave linear results in antioxidant activity of peel extract of Bogor pineapple. Peel and bract (pineapple waste) of Bogor pineapple have potential to develop as sources of natural antioxidant for further exploitation.

\section{REFERENCES}

1. Ohta T, Morinaga H, Yamamoto T, Yamada T. Effect of phlorizin on metabolic abnormalities in spontaneously diabetic torii (SDT) rats. Open J Anim Sci 2012;2(2):113-8

2. Kobori M, Masumoto S, Akimoto Y, Oike H. Phloridzin reduces blood glucose levels and alters hepatic gene expression in normal BALB/c mice. Food Chem Toxicol 2012;50(7):2547-53

3. Sebei K, Gnouma A, Herchi W, Sakouhi F, Boukhchina S. Lipids, proteins, phenolic composition, antioxidant and antibacterial activities of seeds of peanuts (Arachis hypogaea L) cultivated in Tunisia. Biol Res 2013;46(3):257-63.

4. Mokbel MS, Hashinaga F. Antibacterial and antioxidant activities of banana (Musa, AAA cv. Cavendish) fruits peel. Am J Biochem Biotechnol 2005;1(3):125-31.

5. Arya N, Prakash OM, Verma AK, Vivekanand, Pant AK. Variation in antioxidant potential of curcuma longa L. Collected from different ecological niches of western Himalayan region. Int J Pharm Pharm Sci 2015;7(7):85-90

6. Pellegrini N, Serafini M, Colombi B, Rio DD, Salvatore S, Bianchi M, et al. Total antioxidant capacity of plant foods, beverages and oils consumed in Italy assessed by three different in vitro assays. J Nutr 2003;133(9):2812-9.

7. Settharaksa S, Madaka F, Chakree K, Charoenchai L. Total phenolic and flavonoid contents and antioxidant properties of Thai traditional herbal. Int J Pharm Pharm Sci 2014;6(9):564-6.

8. Thaipong K, Boonprakob U, Crosby K, Zevallos LC, Byrne DH. Comparison of ABTS, DPPH, FRAP, and ORAC assays for estimating antioxidant activity from guava fruit extracts. J Food Comp Anal 2006; 19:669-75.

9. Brat P, Hoang LN, Soler A, Reynes M, Brillouet JM. Physicochemical characterization of a new pineapple hybrid (FLHORAN41 Cv.). J Agric Food Chem 2004;52(20):6170-7.

10. Mhatre M, Tilak-Jain J, De S, Devasagayam TP. Evaluation of the antioxidant activity of non-transformed and transformed pineapple: A comparative study. Food Chem Toxicol 2009;47(11):2696-702.
11. Lu XH, Sun DQ, Wu QS, Liu SH, Sun GM. Physico-chemical properties, antioxidant activity and mineral contents of pineapple genotypes grown in china. Molecules 2014;19(6):8518-32.

12. Blois MS. Antioxidant determination by the use of stable free radicals. Nature 1958;181:1199-2000.

13. Benzie IF, Strain JJ. The ferric reducing ability of plasma (FRAP) as a measure of antioxidant power: The frap assay. Anal Biochem 1996;239(1):70-6.

14. Pourmorad F, Hosseinimehr SJ, Shahabimajd N. Antioxidant activity, phenol and flavonoid content of some selected Iranian medicinal plants. Afr J Biotechnol 2006;5(11):1142-5.

15. Chang CC, Yang MH, Wen HM, Chern JC. Estimation of total flavonoid content in propolis by two complementary colorimetric methods. J Food Drug Anal 2002;10(3):178-82.

16. Apak R, Gorinstein S, Böhm VK, Schaich MK. Methods of measurement and evaluation of natural antioxidant capacity and activity: IUPAC technical report. Pure Appl Chem 2013;85:957-98.

17. Prior RL, Wu X, Schaich K. Standardized methods for the determination of antioxidant capacity and phenolics in foods and dietary supplements. J Agric Food Chem 2005;53(10):4290-302.

18. Li XC, Wang XZ, Chen DF, Chen SZ. Antioxidant activity and mechanism of protochatechuic acid in vitro. J Funct Food Health Dis 2011;1(7):232-44

19. Li T, Shen P, Liu W, Liu C, Liang R, Yan N, et al. Major polyphenolics in pineapple peels and their antioxidant interactions. Int J Food Properties 2014; $17: 1805-17$.

20. Kongsuwan A, Suthiluk P, Theppakorn T, Srilaong V, Setha S. Bioactive compounds and antioxidant capacities of phulae and nanglae Pineapple. Asian J Food Agro Ind 2009;2:S44-50.

21. Haripyaree A, Guneshwor K, Damayanti M. Evaluation of antioxidant properties of phenolics extracted from Ananas comosus L. Notulae Sci Biol 2010;2(2):68-71.

22. Rashad MM, Mahmoud AE, Ali MM, Nooman MU, Al-Kashef AS. Antioxidant and anticancer agents produced from pineapple waste by solid state fermentation. Int J Toxicol Pharmacol Res 2015;7(6):287-96.

23. Barreira JC, Ferreira IC, Oliveira MB, Pereira JA. Effects of different phenols extraction conditions on antioxidant activity of almond (Prunus dulcis) fruits. J Food Biochem 2009;33(6):763-76.

24. Miliauskas G, Venskutonis PR, van Beek TA. Screening of radical scavenging activity of some medicinal and aromatic plant extracts. Food Chem 2004;85:231-7.

25. Emmanuel EU, Onagbonfeoana ES, Adanma OC, Precious OC, Faith AI, Ndukaku OY. In vivo and in vitro antioxidant and hypolipidemic activity of methanol extract of pineapple peels in Wistar rats. Int J Biosci 2016;8(6):64-72.

26. Sroka Z, Cisowski W. Hydrogen peroxide scavenging, antioxidant and anti-radical activity of some phenolic acids. Food Chem Toxicol 2003;41(6):753-8

27. Heim KE, Tagliaferro AR, Bobilya DJ. Flavonoid antioxidants: Chemistry, metabolism and structure-activity relationships. J Nutr Biochem 2002;13(10):572-84.

28. Mongkolsilp S, Pongbupakit I, Sae-Lee N, Sitthithaworn W. Radical scavenging activity and total phenolic content of medicinal plants used in primary health care. SWU J Pharm Sci 2004;9(1):32-5.

29. Amic D, Davidovic-Amic D, Beslo D, Rastija V, Lucic B, Trinajstic N. SAR and QSAR of the antioxidant activity of flavonoids. Curr Med Chem 2007;14(7):827-45.

30. Fidrianny I, Johan Y, Sukrasno. Antioxidant activities of different polarity extracts from three organs of Makrut lime (Citrus hystrix DC) and correlation with total flavonoid, phenolic, carotenoid content. Asian J Pharm Clin Res 2015;8(4):239-43. 